This paper has established that one of the directions to correct a designer's idea is the close relationship between the metric characteristics of a model and the dynamics of updating the shape structure. The need to convolute information about model varieties of a men's jacket is due to the cyclical nature of fashion. Regression analysis of this study's results has confirmed the impact of the accumulation of quantitative changes in style attributes on the transition to qualitative changes in shape over 15 years. The periodic repeatability of the fiveseam design of a men's jacket as a typical representative indicates the possibility of using clusters of standard elements. Correlation analysis of the update of mobile attributes (an increase along the waistline and the lapel width) confirms a high level of connection with the silhouette characteristic.

Information and analytical material for encoding classification features of the functional components of model designs for an industrial product range collection has been formed. $A$ variant for convoluting the sets of classification features in the process of sampling sorting relative to the basic list of functional nodes has been proposed. The $24 \times 24$ compatibility matrix built makes it possible to apply the morphological box method to compare sample sets. The presence of uniformity of the average value of accumulated frequencies $K_{c . u .}=0.72, K_{t . u}=0.69$ confirms the membership of the sample in the typological series. Having a common encoding system simplifies the selection of models from the internet-based product range collections.

The method of sorting the models-proposals of the resulting layout set has been confirmed by the validity coefficient $K_{v}=0.71$, which makes it possible to verify the perception of a jacket design as a typical representative of modern structure.

Practical recommendations have been compiled on grouping the records of industrial product range collection model codes into industrial series, which enable control over the launch of articles within the manufacturing process

Keywords: interactive layout, model sampling, structural element, men's jacket, convolution matrix

\title{
DEVISING A METHOD FOR THE INTERACTIVE ARRANGEMENT OF STRUCTURAL ELEMENTS OF MEN'S JACKET MODELS
}

\author{
Alla Slavinska \\ Doctor of Technical Sciences, Professor* \\ Serhii Matiukh \\ $\mathrm{PhD}$, Associate Professor, Rector* \\ Viktoria Mytsa \\ $\mathrm{PhD}$, Associate Professor* \\ Oks a a S yrotenko \\ Corresponding author \\ $\mathrm{PhD}$, Associate Professor* \\ E-mail: syrotenko@email.ua \\ Oksana Dombrovska \\ PhD, Associate Professor* \\ *Department Technology and Design of Garments \\ Khmelnytskyi National University \\ Instytuts'ka str., 11, Khmelnytskyi, Ukraine, 29016
}

Received date 20.09.2021 Accepted date 10.01.2022 Published date 24.02.2022
How to Cite: Slavinska, A., Matiukh, S., Mytsa, V., Syrotenko, O., Dombrovska, O. (2022). Development of the method of interactive composition of structural elements of men's jacket models. Eastern-European Journal of Enterprise Technologies, 1 (1 (115)), 56-66. doi: https://doi.org/10.15587/1729-4061.2022.251065

\section{Introduction}

The transitivity of the process of modification transformations of shape at the stages of design preparation is explained by the effect of such external factors as the product range type, the degree of fit, materials, and fashion [1,2]. European men's suit is an example of the style formation in the cultural heritage of modern clothing [3].

The fuzzy logic of Internet marketing of case studies regarding a fashionable product in the sequence «Design reflection - evaluation - regulation» does not resolve the issue of stable consumer behavior when choosing articles [4,5]. The flexibility of production re-engineering in classical modification is achieved by joining, simplifying, reducing, providing for new combinations of elements of the technical object, provided that the range options are known [6]. The engineering method of designing structures with a focus on popular style lines of a men's jacket [7] contributes to the improvement of logistics service. This approach ensures the formation of clusters of attributes of the design style of an article.
Accordingly, it is a relevant study that aims to formalize the components of modification elements for the layout of an object by tools to assemble unified nodes.

\section{Literature review and problem statement}

Paper [8] reports the results of research into the convolution of information regarding the development of patterns of fashion cyclicality in a classic men's jacket. The confrontation between changes in geometric and plastic shapes is shown, which makes it possible to graphically represent structural schemes of changes in quantitative and qualitative parameters. However, the issues remain unresolved related to the change in quantitative and qualitative parameters of the length of the jacket. This does not allow the use of a fuzzy clustering method to assess the suitability of a representative of fashion design [9]. The reason for this may be objective difficulties in assessing the aesthetic fitness indicators of a representative of fashion design. 
An option to overcome the corresponding difficulties may be a role theory. This approach is used in work [10], which makes it possible to perform case studies of a fashion product based on the validity of communications in the study of requests by specialists.

All this suggests that it is advisable to conduct a study aimed at raising consumer awareness of the varieties of a product range based on the genetic algorithm of relation to purchases discussed in [11]. In particular, the men's suit is formed on the traditions of European culture and still has a global application in the social sphere. This is confirmed by research on the development of the structure of the shape of the men's jacket in the twentieth century [12]. The theoretical model of forecasting the parameters of the shape is the basis for the formation of the base of model features of modifications of a typical representative of the jacket. However, the issues remain unresolved that are related to studies of the model ranges throughout 2000-2020. This approach is used in work [13]. However, the aspect of the social psychology of clothing does not form theoretical approaches to the consideration of the range of clothes as an incentive for behavior and substantive relationships with the individual

An option for overcoming the difficulties of predicting the parameters of shape may be an algorithm of the interactive process of virtual modeling of clothes [14]. It is this approach to assess the suitability of the model ranges that should be considered as an alternative technique.

The option of consuming the «fashion lines» of the men's jacket in the globalization of the market creates prerequisites for the modular design of a stable product range [15]. It is shown that the positioning of modules of the same type affects the gradation of the design state of the object. However, unresolved issues remain that are related to the assessment of the functionality of an article from the sorting positions of types of models. The reason for this may be objective difficulties associated with the predefined setting of parameters in a specific product range, which complicates the procedure for the use of smart technologies [16]. An option to overcome the corresponding difficulties may be to use the procedure of sorting model parameters. This approach minimizes the convolution of model series into an industrial product range collection, according to the needs of the manufacturer.

All these seminal ideas suggest that it is advisable to conduct a study aimed at devising a method for the interactive layout of the verbal codes of structural elements of the men's jacket to improve the design preparation of production.

\section{The aim and objectives of the study}

The purpose of this study is to develop components of the interactive layout of the model range of a men's jacket by means to assemble modification elements. This would reduce the cost part of the gradation of the transition of the structural states of the men's jacket at the stages of design preparation of production.

To accomplish the aim, the following tasks have been set:

- to analytically substantiate a method for combining a designer's idea of signs of the appearance of a men's jacket;

- to construct a matrix of the interactive sorting of variants of the structural and compositional solutions for a men's jacket;

- to devise a procedure for assessing the structural and technological uniformity of interchangeable models for manufacturing them according to the technological process.

\section{The study materials and methods}

\section{1. Methods for studying the transitivity of the pro- cess of modification changes in the men's jacket in the evolution of shape}

Manifestations of fashion cyclicality in the chronology of the evolution of shape have been theoretically substantiated in the methodology reported in [17], which makes it possible to investigate probable changes in the structure of the shape based on the previous development. Synergistic connections within the system «shape - objective function» in the demand assessment are characterized by the historical depth of statistical research.

For practical purposes, the most important is the recommendation for the manifestation of the most stressed geometric structures for 11-12 years, as well as the forecast of probable expectation of fashionable shapes within 2-3 years, which is confirmed by studies $[8,12]$. Thus, the optimal duration of the time cycle is 15 years, which consists of a 12-year period of development of the basic shape and a three-year period of the transitional structure of the shape.

To determine the degree of interrelation between the attributes of shape structure, it is advisable to use the method of correlation analysis of statistical data.

To test the opinion on the selective function of fashion in the form of a traditional men's jacket, two sampling areas of statistical characteristics of product range models were selected: 1 - 1970-2000 [12], 2 - 2000-2020 [7].

The sample set $X_{1}$ is a subset in the set of samples $X_{2}, X_{1} \subset X_{2}$. The mathematical notations of operations on the sets are as follows: the membership of an element of the sets $x \in X_{1}$, the combination (sum) of sets $X_{3}=X_{1} \cup X_{2}=\left\{x \mid x \in X_{1}\right.$ or $x \mid x \in X_{2}$. The intersection of sets $\bar{X}_{3}=X_{1} \cap X_{2}=\left\{x \mid x \in X_{1}, x \in X_{2}\right\}$ provides for the properties of communication and associativity when comparing the samples.

The verification of model images in modern systems of clothes computer-automated design (CAD) «Clothes» involves the clusters of group attributes of appearance (AoA) [18]. At the enterprise level, the classification system is subject to the use of design features in line with the technological capabilities of production.

The classification system of optimized selection of prototype categories [19] creates prerequisites for simplifying the parallel encoding method. The use of the method of visual expert evaluation of the design idea of novelty levels of articles in the loop of the fashion life cycle «high - modern - mass outdated» makes it possible to evaluate the production feasibility of the transaction of typical representatives of the shape.

4. 2. Matrix approach to the modification sorting of compositional and structural solutions for a men's jacket

The presence of auto-correction in the dynamics of alternating silhouette shapes explains the period of shift for 3 years in the cycle of development of the basic shape [12]. Correlation analysis of the set of classification features of a men's jacket ensures the selection of types of subordination of appearance features within the silhouette shape. In particular, type I - a fitting silhouette, type I - a semi-fitting silhouette, type 3 - a straight silhouette based on the principle AND-OR.

The presence of a significant number of variants of individual design solutions (IDS) $a_{1}$ of the functional node $b$ of an article in the form of logical variables states the task of structural synthesis of the subset $\bar{X}$ in the form of a Boolean matrix of relations: 


$$
\bar{X}=\prod_{i=1}^{b} X_{i}=\left\{x_{a i}\right\} ; 1 \leq b ; 1 \leq a_{i} \leq A_{i}
$$

where $b$ is the number of functional components in an article; $A_{1}$ is the number of variants of IDS of the $i$-th node.

The compatibility summary matrix makes it possible to select the subsets of all possible complex design solutions (CDS):

$$
\bar{X}=\left(X_{a 1}^{(1)}, \ldots . X_{a b}^{b}\right) \in X \leftrightarrow X_{a 1}^{(1)}, \ldots X_{a b}^{b},
$$

which are pairwise compatible.

The presence of a compatibility matrix eliminates the likelihood of skipping or re-examining possible IDS connections.

Motivated reduction of IDS is performed according to the results of correlation analysis in the selected period, based on the description of the conditional model of the typical representative of a traditional men's jacket.

Two blocks of information are recommended for a conditional model description. The first block includes the attributes of the appearance, AoA, which are divided into two groups: the nominal signs of production feasibility (article name, silhouette, the type of material); the main features of the design idea (from the technical description of the model). The second block contains a list of functional components of an article, taking into consideration the splitting into the main parts (back, peel, sleeve) and the use of functional and decorative parts (collar, clasping, board, bottom, pockets, etc.). The formation of a morphological card of the main and additional attributes of appearance should take into consideration the strategy of emotional branding in creating a style [20].

Thus, to construct a matrix of the optimal combinations of structural elements of the model solution, it is advisable to use the morphological box method.

Because the number of rows in a matrix is equal to the number of its columns, the matrix is called square. The diagonal of binary combinations of the same-name codes contains elements $A^{g}=a_{i j}^{g}=0$, which exclude the compatibility with itself.

4. 3. Methods of estimation of the structural and technological continuity of industrial collection models

The main requirements for models of the industrial product range collection of clothing are production and technological homogeneity, compatibility, and interchangeability. To sort the model range of composite proposals for a typical representative, the theoretical basis is to use two modification principles [15].

According to the first principle, model designs of the series (MDS) of clothing are constructed on the basis of a single typical basic structure - the basis of the series. These series are a set of modifications of design options for the same or diverse purpose, the main characteristics of which (silhouette, cut of basic parts, cutting methods) are inherent in typical basic designs. Secondary features (clasps, collar, trim, pockets, etc.) are inherent in various modifications of the series, that is, they are derived from the selected base.

According to the second principle, modules of variants of typical unified basic and derivative parts are used to design the series:

$$
[S M] \subset F N_{1, \ldots k} \subset P_{1, \ldots e} \in C M_{1, \ldots i}
$$

where $S M$ is the series of model structures; $F N_{1, \ldots k}$ is an integral part in the form of a functional node; $P_{1, \ldots e}$ is the variant of modification of a part's designs; $C M_{1, \ldots i}$ is the structural elements of the structural module in geometric and functional interchangeability.

The use of a modular approach ensures the compatibility of unified components both in size and in terms of the functional feasibility of the design idea.

In the technological process, it is recommended to produce from 3 to 6 models simultaneously. The expediency of launching the process is characterized by the same type of design names of basic parts in functional nodes $(K)$, the interchangeability of design of functional and decorative parts $(P)$, the similarity of technological properties of materials $(M)$.

Thus, the size of a product range collection is determined from the following formula:

$$
N=K \times P \times M .
$$

The criteria for assessing the structural and technological continuity of models in the series are coefficients of the structural $K_{\text {c.u. }}$ and technological $K_{t . u}$. uniformity:

$$
K_{c . u .}=\frac{\sum m_{i j}}{\sum M_{i j}} ; K_{t . u .}=\frac{\sum c_{i j}}{\sum C_{i j}},
$$

where $\Sigma m_{i j}$ is the number of the same design features; $\Sigma M_{i j}$ is the number of all design features; $\Sigma c_{i j}$ is the number of homogeneous technological signs of complex processing; $\Sigma C_{i j}$ is the number of all technological features that determine the complexity of processing.

On average, $K_{c . u}$ and $K_{t . u}$ for a men's jacket do not exceed 0.8 . Selection of models for simultaneous production in the technological process should be used in pairwise comparison, for example, A, B; B, C; A, C.

\section{Results of studying the interactive layout of models for a classic men's jacket}

5. 1. Analytical method of combining a designer's idea in a typical representation of attributes of appearance of a men's jacket

On the principle of continuity, clothing design can be attributed to the second group of plastic arts - architectonics; it is a product of design.

The most effective in building predictive models of the attributes of the appearance of an article is a regressive analysis of the figurativeness indicators of the design idea about a shape according to style. Periodic repetition of cyclical fashion confirmed the viability of classic shapes of a men's jacket, the production feasibility of which is testified to by the transitivity of the silhouette of a typical five-seam structure of basic parts (Fig. 1) [7].

The utilitarian content of varying the area of limitation of the silhouette margin contour in the articles of a jacket group over a 12 -year period $\left(a_{s}=1.83 \mathrm{~cm}\right)$ confirms the match with the interval of dimensional indifference of $2.0 \mathrm{~cm} \mathrm{[21].}$

To study ever-changing models of a traditional men's jacket, a restriction chosen is the consumer category «stabilizers», the normalized series of silhouetted margins, and a typical five-seam body design [15].

The reliability of scaling the ODR relative to the natural proportions of a human figure is ensured by tools for computer technologies to typify the size of an object [22]. 


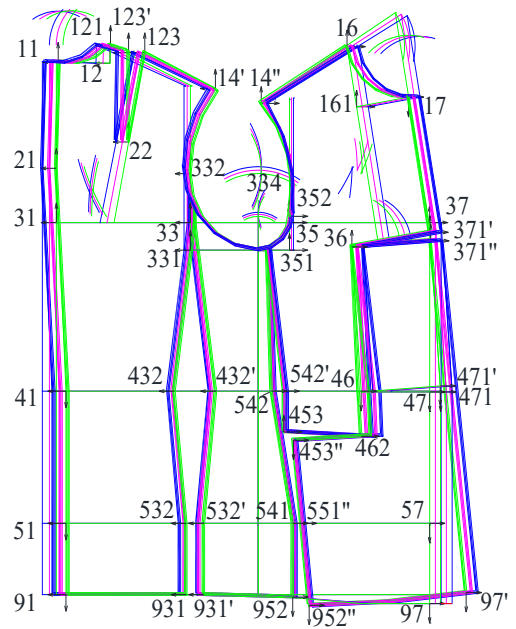

Fig. 1. Silhouette modification of the structure of the body of a men's jacket: $--\mathrm{Si} 1$ (fitting); $--\mathrm{Si} 2$ (semi-fitting); $-\mathrm{Si}$ (straight)

Mathematical modeling of the dynamics of updating the shape of a men's jacket over the period 1970-2000 [12] made it possible to characterize the homogeneity of the frequency distribution of and the type of modifications of main components to substantiate the input data on ODR grouping. The basis for grouping is indicators of stability and mobility of structural features. According to the estimation scale of the closeness of link, it was found that the stable attributes of shape structure (waist, upper loop, shoulder height) are characterized by a satisfactory link $(0.567 ; 0.499 ; 0.543)$. The mobile attributes of the structure (shoulder width level, lapel width, breast line margin) are characterized by a strong link (0.784; 0.802; 0.856) (Table 1).

Checking the auto-correlation according to the Durbin Watson statistic $\left(d_{\text {calc }}=0.813<d_{2}=1.08\right)$ confirmed the confrontation between the dynamics of plastic and geometric shapes (Fig. 2).

The silhouetted affiliation of ACGbII parameters has signs of repeatability of a three-year period in the geometry of the shape (Table 1). Namely: the diffusion of ACGbII values for a fitting silhouette $-y_{2}, y_{3}, y_{9}(6.44 ; 6.62 ; 6.29 \mathrm{~cm})$; for a semi-fitting silhouette $-y_{1}, y_{4}, y_{8}, y_{10}(8.818 ; 9.176$; $6.916 ; 8.32 \mathrm{~cm})$; for a straight silhouette $-y_{5}, y_{6}, y_{7}(11.773$; $12.019 ; 9.684 \mathrm{~cm})$. This allows us to assume the preservation of 15-year cycles of shape development: plastic shape 1971-1986, 2003-2018; geometric shape - 1987-2002, 2019 to the present.

The role of the composition center in a men's jacket belongs to the lines of the collar, lapel, and board, which dominate over the rest of the decorative lines of an article. Correlation analysis of the subordination of lapel width and silhouette in the sample range of 2003-2018 confirms hypothetically the same nature of the distribution of lapel width and silhouette. In particular, narrow lapels and a straight silhouette $(\eta=0.81)$, medium lapels and a semi-fitting silhouette $(\eta=0.73)$, wide lapels and a fitting silhouette $(\eta=0.997)$ (Fig. 3).
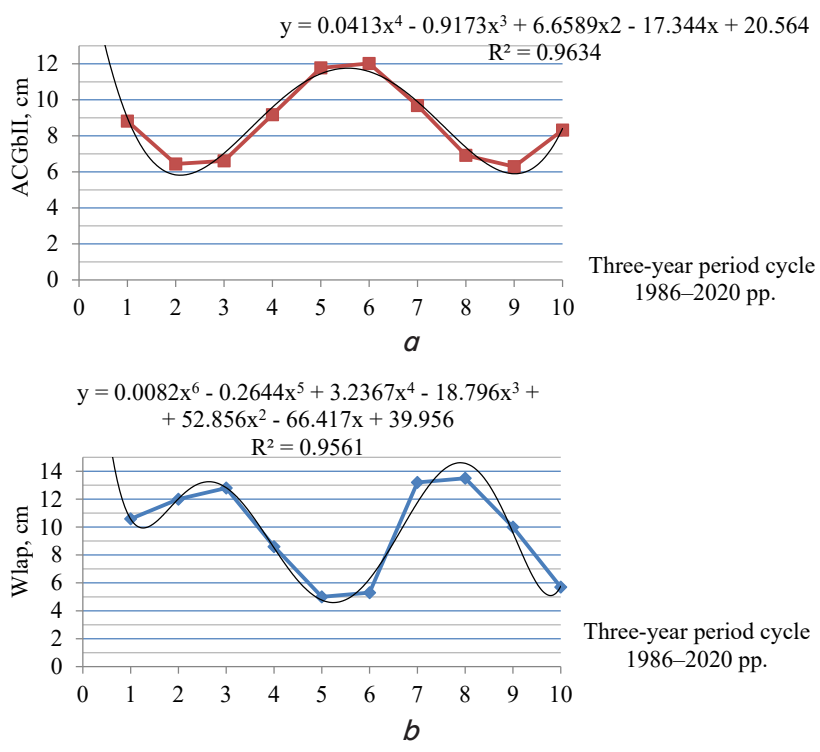

Fig. 2. Harmonics of mobile metric characteristics: $a-$ an increase in the breast line, ACGbll; $b$ - lapel width, Wlap

The first type of combination of design solutions of the semi-fitting silhouette $(\bar{X}=61.8 \%)$ characterizes the level above the average occurrence. The second type determines the signs of a fitting silhouette $(\bar{X}=15.5 \%)$, the third type combines the attributes of a straight silhouette $(\bar{X}=14.8 \%)$. An indefinite type of combinations of structural solutions $(\bar{X}=8.2 \%$ ) was excluded from the analysis as the effect of scattering.

The high level of silhouette correlation with a lapel width parameter indicates the possibility of determining the transition point to the plastic shape. The stable dominance of a semi-fitting silhouette $\bar{X}=61.8 \%$ makes it possible to highlight a cluster of the structurally unified series of typical design solutions for a men's jacket (Fig. 3), confirmed by data reported in $[15,23]$.

Statistics of the design features of the style lines of a men's jacket in the XXI century [7, 24, 25] characterize the set $X_{1}$. The grouping of classification features of the structurally unified series [15] characterizes the set $X_{2}: X_{1} \subset X_{2}$. The model series of elements of the set $X_{2}$ forms subsets of the combination $\bar{X}_{3}=X_{1} \cup X_{2}$ and $\bar{X}_{4}=X_{1} \cap X_{2}$, which provides the conditions for sorting clusters of the structural-model series to highlight the model series of the industrial product range collection [26].

Table 1

Experimental harmonics of the dynamic series of mobile features in the structure of the shape of a men's jacket

\begin{tabular}{|c|c|c|c|c|c|c|c|c|c|c|c|c|c|c|c|c|}
\hline \multirow{3}{*}{$\begin{array}{c}\text { Matrix } \\
\text { parameters, cm }\end{array}$} & \multicolumn{16}{|c|}{ Interpolation of a function by a trigonometric Fourier polygon } \\
\hline & \multirow{2}{*}{ K } & \multirow{2}{*}{$a_{0}$} & \multirow{2}{*}{$a_{k}$} & \multirow{2}{*}{$b_{k}$} & \multirow{2}{*}{$y_{0}$} & \multicolumn{5}{|c|}{$1987-2002$} & \multicolumn{5}{|c|}{$2003-2018$} & \multirow{2}{*}{$\eta$} \\
\hline & & & & & & $y_{1}$ & $y_{2}$ & $y_{3}$ & $y_{4}$ & $y_{5}$ & $y_{6}$ & $y_{7}$ & $y_{8}$ & $y_{9}$ & $y_{10}$ & \\
\hline $\begin{array}{l}\text { Breast line margin, } \\
\text { ACGbII }\end{array}$ & 1 & 9.119 & -0.284 & 1.796 & 10.133 & 8.818 & 6.44 & 6.612 & 9.176 & 11.773 & 12.019 & 9.684 & 6.916 & 6.29 & 8.32 & 0.856 \\
\hline Lapel width, Wlap & 1 & 9.261 & -0.700 & 4.673 & 12.815 & 10.589 & 12.0 & 12.8 & 8.6 & 5.0 & 5.3 & 13.2 & 13.5 & 10.0 & 5.7 & 0.802 \\
\hline
\end{tabular}



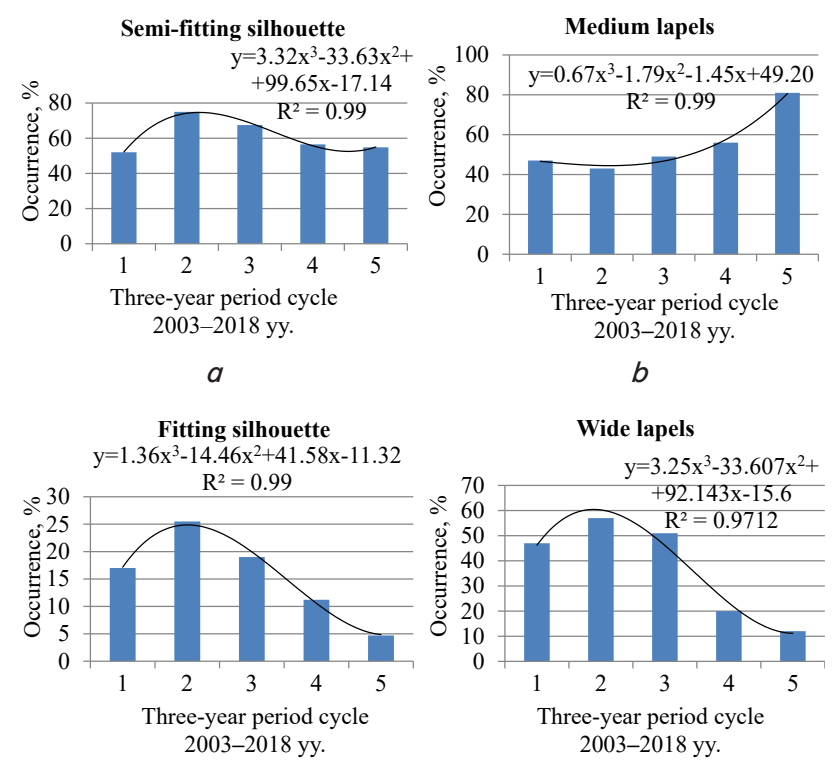

c

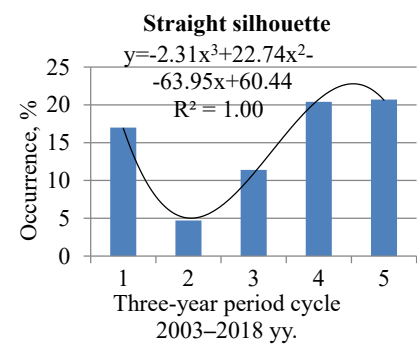

e
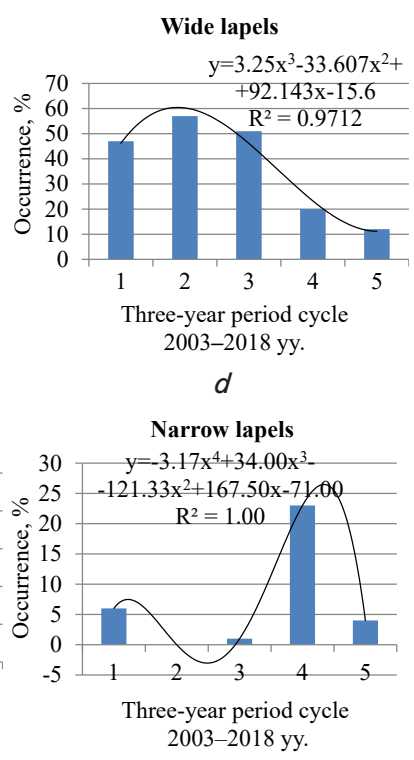

$f$

Fig. 3. Graphic interpretation of the occurrence of mobile attributes in the silhouette types of a men's jacket: $a$ - semi-fitting silhouette; $b$ - medium lapels; $c$ - fitting silhouette; $d$ - wide lapels; $e-$ straight silhouette; $f-$ narrow lapels

5. 2. Building a compatibility matrix for the automated layout of typical design solutions for men's jacket models

Men's gender differences in relation to fashion are based on social identity and then uniqueness, which explains a certain conservatism of perception of the jacket.

We group the typical classification attributes of the appearance of a men's jacket on the principle AND-OR relative to ten characteristics. Silhouette - semi-fitting, fitting, or straight. Shoulders - normal or enlarged. Clasp - open central or shifted, at 1-4 buttons. The board is straight or rounded. Collar - jacket-type; lapels - medium or wide, or narrow, straight, or dull, or sharp. Upper pocket - cut or attached, or absent. Side pockets - through or attached. The back is with a middle seam, or with ventricles, or with a sash in the side seams. Front - with a cut-off side or with darts. Sleeve - sewing two-seam with a ventricle.

The encoding of the ciphers of the typical representatives of the appearance of the men's jacket according to the results of cluster analysis of the style lines throughout 2003-2018 ( $\left.\operatorname{set} X_{1}\right)$ is given in Table 2 .

The encoded record of eight functional nodes is formed on the basis of ensuring the objective function in the design on the principle of similarity to a typical representative.

The typifying of IDS in functional nodes is represented by 24 variants of model IDS. The size of the symmetrical square matrix is $24 \times 24$. To depopulate the matrix, we used the following symbols: 1 - compatible, 0 - incompatible in the industrial product range collection of a men's jacket (subset $\bar{X}_{3}$ ) (Table 3$)$.

Table 2

Encoding the classification features of the functional units of model structures for industrial product range collections of a modern jacket

\begin{tabular}{|c|c|c|}
\hline $\begin{array}{l}\text { Code and name } \\
\text { of the functional } \\
\text { node }\end{array}$ & IDS cipher & Classification attribute title \\
\hline \multirow{4}{*}{ 1. Back } & 1.1 & Middle seam without slots \\
\hline & 1.2 & Middle seam with slot \\
\hline & 1.3 & $\begin{array}{l}\text { Middle seam, slot in the side } \\
\text { seam }\end{array}$ \\
\hline & 1.4 & Middle seam, yoke \\
\hline \multirow{3}{*}{ 2. Pilochka } & 2.1 & Cutting side and combined dart \\
\hline & 2.2 & Cutting side and thallium dart \\
\hline & 2.3 & Cutting side and yoke \\
\hline \multirow{2}{*}{ 3. Sleeve } & 3.1 & $\begin{array}{l}\text { Sutured, double-stitched, with } \\
\text { a closed slot }\end{array}$ \\
\hline & 3.2 & $\begin{array}{l}\text { Sutured, double-stitched, with } \\
\text { open slot }\end{array}$ \\
\hline \multirow{3}{*}{ 4. Collar } & 4.1 & Jacket-type, with narrow lapels \\
\hline & 4.2 & Jacket-type, with medium lapels \\
\hline & 4.3 & Jacket-type, with wide lapels \\
\hline \multirow{3}{*}{ 5. Clasp } & 5.1 & $\begin{array}{l}\text { Central, open, with hinges and } \\
\text { buttons, the board is straight }\end{array}$ \\
\hline & 5.2 & $\begin{array}{l}\text { Central, open, with loops and } \\
\text { buttons, the board is rounded }\end{array}$ \\
\hline & 5.3 & $\begin{array}{l}\text { Offset, on the hinges and } \\
\text { buttons, the board is straight }\end{array}$ \\
\hline \multirow{3}{*}{ 6. Upper pocket } & 6.1 & Slit with a leaf \\
\hline & 6.2 & Attached \\
\hline & 6.3 & Without a pocket \\
\hline \multirow{3}{*}{ 7. Side pocket } & 7.1 & Slotted, with valve \\
\hline & 7.2 & Perforated, framed \\
\hline & 7.3 & $\begin{array}{l}\text { Attached, with different design } \\
\text { appearance }\end{array}$ \\
\hline \multirow{3}{*}{$\begin{array}{l}\text { 8. The number of } \\
\text { buttons for the } \\
\text { measure of fitting }\end{array}$} & 8.1 & $\begin{array}{l}\text { One loop and a button, the } \\
\text { fitting silhouette }\end{array}$ \\
\hline & 8.2 & $\begin{array}{l}\text { Two loops and buttons, } \\
\text { semi-fitting silhouette }\end{array}$ \\
\hline & 8.3 & $\begin{array}{l}\text { Three or more loops and } \\
\text { buttons, straight silhouette }\end{array}$ \\
\hline
\end{tabular}


Table 3

The compatibility matrix of models in the industrial product range collection of a men's jacket

\begin{tabular}{|c|c|c|c|c|c|c|c|c|c|c|c|c|c|c|c|c|c|c|c|c|c|c|c|c|c|}
\hline \multirow{2}{*}{$\begin{array}{l}\text { Node } \\
\text { code }\end{array}$} & \multirow{2}{*}{$\begin{array}{l}\text { IDS } \\
\text { code }\end{array}$} & \multicolumn{4}{|c|}{1} & \multicolumn{3}{|c|}{2} & \multicolumn{2}{|c|}{3} & \multicolumn{3}{|c|}{4} & \multicolumn{3}{|c|}{5} & \multicolumn{3}{|c|}{6} & \multicolumn{3}{|c|}{7} & \multicolumn{3}{|c|}{8} \\
\hline & & 1.1 & 1.2 & 1.3 & 1.4 & 2.1 & 2.2 & 2.3 & 3.1 & 3.2 & 4.1 & 4.2 & 4.3 & 5.1 & 5.2 & 5.3 & 6.1 & 6.2 & 6.3 & 7.1 & 7.2 & 7.3 & 8.1 & 8.2 & 8.3 \\
\hline \multirow{4}{*}{1} & 1.1 & 0 & 0 & 0 & 0 & 1 & 1 & 1 & 1 & 1 & 0 & 1 & 1 & 1 & 1 & 1 & 1 & 1 & 0 & 1 & 1 & 1 & 1 & 1 & 1 \\
\hline & 1.2 & 0 & 0 & 0 & 0 & 1 & 1 & 1 & 1 & 1 & 1 & 1 & 1 & 1 & 1 & 1 & 1 & 1 & 1 & 1 & 1 & 1 & 0 & 1 & 1 \\
\hline & 1.3 & 0 & 0 & 0 & 0 & 1 & 1 & 1 & 1 & 1 & 1 & 1 & 1 & 1 & 1 & 1 & 1 & 1 & 0 & 1 & 1 & 1 & 1 & 1 & 1 \\
\hline & 1.4 & 0 & 0 & 0 & 0 & 0 & 1 & 1 & 1 & 1 & 1 & 1 & 1 & 1 & 0 & 0 & 1 & 1 & 1 & 0 & 1 & 1 & 0 & 0 & 1 \\
\hline \multirow{3}{*}{2} & 2.1 & 1 & 1 & 1 & 0 & 0 & 0 & 0 & 1 & 1 & 1 & 1 & 1 & 1 & 1 & 1 & 1 & 1 & 0 & 1 & 1 & 1 & 1 & 1 & 1 \\
\hline & 2.2 & 1 & 1 & 1 & 1 & 0 & 0 & 0 & 1 & 1 & 1 & 1 & 1 & 1 & 1 & 1 & 1 & 1 & 1 & 0 & 1 & 1 & 1 & 1 & 1 \\
\hline & 2.3 & 1 & 1 & 1 & 1 & 0 & 0 & 0 & 1 & 1 & 1 & 1 & 1 & 1 & 1 & 1 & 0 & 1 & 1 & 0 & 1 & 1 & 1 & 1 & 1 \\
\hline \multirow{2}{*}{3} & 3.1 & 1 & 1 & 1 & 1 & 1 & 1 & 1 & 1 & 1 & 1 & 1 & 1 & 1 & 1 & 1 & 1 & 1 & 1 & 1 & 1 & 1 & 1 & 1 & 1 \\
\hline & 3.2 & 1 & 1 & 1 & 1 & 1 & 1 & 1 & 1 & 1 & 1 & 1 & 1 & 1 & 1 & 1 & 1 & 1 & 1 & 1 & 1 & 1 & 1 & 1 & 1 \\
\hline \multirow{3}{*}{4} & 4.1 & 0 & 1 & 1 & 1 & 1 & 1 & 1 & 1 & 1 & 0 & 0 & 0 & 1 & 1 & 1 & 1 & 0 & 1 & 1 & 1 & 1 & 1 & 1 & 1 \\
\hline & 4.2 & 1 & 1 & 1 & 1 & 1 & 1 & 1 & 1 & 1 & 0 & 0 & 0 & 1 & 1 & 0 & 1 & 1 & 1 & 1 & 1 & 1 & 1 & 1 & 1 \\
\hline & 4.3 & 1 & 1 & 1 & 1 & 1 & 1 & 1 & 1 & 1 & 0 & 0 & 0 & 1 & 1 & 1 & 1 & 1 & 1 & 1 & 1 & 1 & 1 & 1 & 1 \\
\hline \multirow{3}{*}{5} & 5.1 & 1 & 1 & 1 & 1 & 1 & 1 & 1 & 1 & 1 & 1 & 1 & 1 & 0 & 0 & 0 & 1 & 1 & 1 & 1 & 1 & 1 & 1 & 1 & 1 \\
\hline & 5.2 & 1 & 1 & 1 & 0 & 1 & 1 & 1 & 1 & 1 & 1 & 1 & 1 & 0 & 0 & 0 & 1 & 1 & 1 & 1 & 1 & 1 & 1 & 1 & 1 \\
\hline & 5.3 & 1 & 1 & 1 & 0 & 1 & 1 & 1 & 1 & 1 & 1 & 0 & 1 & 0 & 0 & 0 & 1 & 0 & 1 & 1 & 1 & 1 & 0 & 1 & 1 \\
\hline \multirow{3}{*}{6} & 6.1 & 1 & 1 & 1 & 1 & 1 & 1 & 0 & 1 & 1 & 1 & 1 & 1 & 1 & 1 & 1 & 0 & 0 & 0 & 1 & 1 & 1 & 1 & 1 & 1 \\
\hline & 6.2 & 1 & 1 & 1 & 1 & 1 & 1 & 1 & 1 & 1 & 0 & 1 & 1 & 1 & 1 & 0 & 0 & 0 & 0 & 1 & 1 & 1 & 0 & 1 & 1 \\
\hline & 6.3 & 0 & 1 & 0 & 1 & 0 & 1 & 1 & 1 & 1 & 1 & 1 & 1 & 1 & 1 & 1 & 0 & 0 & 0 & 1 & 1 & 1 & 0 & 1 & 1 \\
\hline \multirow{3}{*}{7} & 7.1 & 1 & 1 & 1 & 0 & 1 & 0 & 0 & 1 & 1 & 1 & 1 & 1 & 1 & 1 & 1 & 1 & 1 & 1 & 0 & 0 & 0 & 1 & 1 & 1 \\
\hline & 7.2 & 1 & 1 & 1 & 1 & 1 & 1 & 1 & 1 & 1 & 1 & 1 & 1 & 1 & 1 & 1 & 1 & 1 & 1 & 0 & 0 & 0 & 1 & 1 & 1 \\
\hline & 7.3 & 1 & 1 & 1 & 1 & 1 & 1 & 1 & 1 & 1 & 1 & 1 & 1 & 1 & 1 & 1 & 1 & 1 & 1 & 0 & 0 & 0 & 0 & 1 & 1 \\
\hline \multirow{3}{*}{8} & 8.1 & 1 & 0 & 1 & 0 & 1 & 1 & 1 & 1 & 1 & 1 & 1 & 1 & 1 & 1 & 0 & 1 & 0 & 0 & 1 & 1 & 0 & 0 & 0 & 0 \\
\hline & 8.2 & 1 & 1 & 1 & 0 & 1 & 1 & 1 & 1 & 1 & 1 & 1 & 1 & 1 & 1 & 1 & 1 & 1 & 1 & 1 & 1 & 1 & 0 & 0 & 0 \\
\hline & 8.3 & 1 & 1 & 1 & 1 & 1 & 1 & 1 & 1 & 1 & 1 & 1 & 1 & 1 & 1 & 1 & 1 & 1 & 1 & 1 & 1 & 1 & 0 & 0 & 0 \\
\hline
\end{tabular}

The matrix of combinations of elements relative to the main diagonal of size $l \times n$ defines a subset of combinations $N_{c}^{p}=421$, where a subset of combination 0 characterizes zeros in the diagonal and the absence of the IDS variant $N^{0}=56+21=77$.

The coefficient of sparsity of connections in the matrix $m_{3}$ is determined from the formula:

$$
m_{X_{3}}=\frac{N^{0}}{N_{c}^{p}}=\frac{77}{421}=0.183
$$

where $N^{0}$ is the subset of combinations $0 ; N_{c}^{p}$ is the subset of the matrix of dimensionality $l \times n$.

According to the results of the automated construction of the compatibility matrix of the industrial product range collection of a men's jacket (set $X_{1}$ ), the maximum number of models was 5,832. Among them, we highlighted the codes $N_{f}=908$ of the actual models (set $X_{2}$ ). The convolution $N_{\max }$ explains the exclusion of $N_{f}$ due to zero pairings: $N_{\max }-N_{f}=5,832-908=4,924$.
Control of the sparsity coefficient in the code record of models is calculated from the formula:

$$
m_{X_{4}}=\frac{908}{4,924}=0.184
$$

The error in the actual arrangement of proposals-models of $0.1 \%$ confirms the preservation of the cyclical nature of structural elements of the shape of a typical representative of the traditional men's jacket.

5. 3. Procedure for assessing the structural and technological homogeneity of the combination of interchangeable models

The composition of models in the industrial product range collection of a men's jacket combines the plastic shape of design idea (DI) and production feasibility (PF) of technical capabilities for the production of competitive products.

The size of the rational industrial product range collection $C_{\text {rat }}$, taking into consideration clusters from Table 2, is 18 units: 


$$
C_{\text {rat }}=P \times M \times K=3 \times 2 \times 3=18,
$$

where $P$ is a cluster of the types of functional nodes, $P=3$; $M$ is the cluster of indicators of DI and PF geometry, $M=2$; $K$ is the cluster of silhouettes, $K=3$.

To combine models from the industrial collection in a series, subject to manufacturing involving a typical technological process, it is necessary to take into consideration a number of requirements:

- commonness of the basic base, the similarity of raw materials, close labor intensity, processing identity;

$-K_{c . u .}, K_{t . u .}=0.6-0.8$;

- the repeatability of indicators of typical representation over $45 \%$;

- the repetition of style indicators in modifications of the design idea - from 25 to $45 \%$;
- ensuring the variability of the image of models according to the originality of the composition tools (color, texture, shape) - up to $25 \%$ (from 5 to 8 indicators of novelty).

The number of silhouettes of basic bases (fitting, semi-fitting, straight) determines the number of industrial series -3 . In each industrial series, for simultaneous launch in the technological process, we imply 3 models (the multiplicity of number 3 ).

Sorting the clusters of analog model codes (set $X_{1}$, 35 models), proposed models (set $X_{2}, 908$ models), the structurally unified series by the attributes of typification in $X_{2}$ (a subset of averages $\bar{X}_{3}$ ); sorting IDS polygons in the subset $\bar{X}_{3}$ (a subset of averages $\bar{X}_{4}$ ) are given in Table 4 . The diagram of occurrence in the set $X_{2}$ is shown in Fig. 4 .

The above indicators of accumulated occurrences are used to calculate the uniformity of the structural elements of FN (Table 5).

Sorting matrix of arranging IDS of functional nodes in a men's jacket's proposed models

Table 4 into the clusters of average samples $\bar{X}_{3}, \bar{X}_{4}$

\begin{tabular}{|c|c|c|c|c|c|c|c|c|c|c|c|c|c|}
\hline \multirow{3}{*}{$\begin{array}{l}\text { FN } \\
\text { code }\end{array}$} & \multirow{3}{*}{$\begin{array}{l}\text { IDS } \\
\text { code }\end{array}$} & \multicolumn{6}{|c|}{ Sorting the IDS polygons } & \multicolumn{2}{|c|}{ The subset of averages } & \multirow{3}{*}{$\begin{array}{c}\text { Deviation } \\
\bar{X}_{4}-X_{2}\end{array}$} & \multirow{3}{*}{$\Delta_{2}=\bar{X}_{4}-\bar{X}_{3}$} & \multirow{3}{*}{$\bar{\Delta}_{\text {aver }}$} & \multirow{3}{*}{$\begin{array}{l}\text { Typifica- } \\
\text { tion index }\end{array}$} \\
\hline & & \multicolumn{2}{|c|}{ Sample of sets } & \multicolumn{4}{|c|}{ Sorting the FN functional nodes } & \multirow{2}{*}{$\begin{array}{c}\bar{X}_{3} \\
1.1-1.4\end{array}$} & \multirow{2}{*}{$\begin{array}{c}\bar{X}_{4} \\
-\end{array}$} & & & & \\
\hline & & $X_{1}$ & $X_{2}$ & 1.1 & 1.2 & 1.3 & 1.4 & & & & & & \\
\hline \multirow{4}{*}{1} & 1.1 & 40.0 & 27.3 & 33.65 & - & - & - & 33.65 & 36.83 & 9.53 & 3.17 & 6.35 & $\mathrm{~T}$ \\
\hline & 1.2 & 20.0 & 38.8 & - & 29.4 & - & - & 29.4 & 24.7 & 14.1 & 4.7 & 9.4 & $\mathrm{M}$ \\
\hline & 1.3 & 34.3 & 30.8 & - & - & 32.55 & - & 32.55 & 33.43 & 2.63 & 0.84 & 1.75 & $\mathrm{M}$ \\
\hline & 1.4 & 5.7 & 3.1 & - & - & - & 4.4 & 4.4 & 5.05 & 1.95 & 0.65 & 1.3 & $\mathrm{O}$ \\
\hline \multirow{3}{*}{2} & 2.1 & 57.1 & 50.2 & 58.1 & 40.9 & 60.0 & 0.0 & 53.0 & 51.6 & 2.6 & 5.5 & 3.05 & $\mathrm{~T}$ \\
\hline & 2.2 & 28.6 & 30.4 & 29.0 & 31.8 & 28.6 & 42.9 & 33.1 & 31.75 & 1.35 & 3.15 & 2.25 & $\mathrm{M}$ \\
\hline & 2.3 & 14.3 & 19.4 & 12.9 & 27.3 & 11.4 & 57.2 & 27.2 & 23.3 & 3.9 & 9.0 & 6.45 & $\mathrm{O}$ \\
\hline \multirow{2}{*}{3} & 3.1 & 40.0 & 50.2 & 50.0 & 60.0 & 50.7 & 50.0 & 52.6 & 45.3 & 4.9 & 5.3 & 5.1 & $\mathrm{~T}$ \\
\hline & 3.2 & 50.0 & 49.8 & 49.2 & 50.0 & 49.3 & 50.0 & 49.6 & 42.8 & 7.0 & 7.2 & 7.1 & $\mathrm{~T}$ \\
\hline \multirow{3}{*}{4} & 4.1 & 29.6 & 15.9 & 12.9 & 17.1 & 15.7 & 28.6 & 18.57 & 17.2 & 1.3 & 12.4 & 6.85 & $\mathrm{O}$ \\
\hline & 4.2 & 45.7 & 43.2 & 43.6 & 36.1 & 41.4 & 71.4 & 47.9 & 46.79 & 3.59 & 1.09 & 2.38 & $\mathrm{~T}$ \\
\hline & 4.3 & 25.7 & 40.9 & 43.6 & 32.7 & 42.9 & 0.0 & 29.8 & 35.35 & 5.55 & 9.65 & 7.6 & $M$ \\
\hline \multirow{3}{*}{5} & 5.1 & 20.0 & 43.4 & 49.6 & 42.1 & 43.9 & 0.0 & $\begin{array}{l}33.9 \\
\end{array}$ & 38.65 & 4.75 & 18.65 & 11.7 & $\mathrm{M}$ \\
\hline & 5.2 & 65.7 & 47.1 & 50.4 & 42.9 & 44.7 & 85.0 & 55.8 & 51.4 & 4.33 & 14.3 & 9.42 & $\mathrm{~T}$ \\
\hline & 5.3 & 14.3 & 9.5 & 0.0 & 14.2 & 11.4 & 14.3 & 9.97 & 9.73 & 0.237 & 4.57 & 2.4 & $\mathrm{O}$ \\
\hline \multirow{3}{*}{6} & 6.1 & 74.3 & 48.8 & 54.8 & 37.2 & 59.3 & 14.3 & 41.4 & 45.1 & 3.7 & 32.9 & 18.3 & $\mathrm{~T}$ \\
\hline & 6.2 & 11.4 & 40.3 & 45.2 & 37.5 & 40.7 & 28.6 & 38.0 & 39.15 & 1.15 & 27.75 & 15.95 & $\mathrm{M}$ \\
\hline & 6.3 & 14.3 & 10.9 & 0.0 & 25.3 & 0.0 & 57.2 & 20.63 & 15.76 & 4.86 & 1.46 & 3.16 & $\mathrm{O}$ \\
\hline \multirow{3}{*}{7} & 7.1 & 48.6 & 44.6 & 41.5 & 47.7 & 42.9 & 50.0 & 45.5 & 45.06 & 0.46 & 3.1 & 1.78 & $\mathrm{~T}$ \\
\hline & 7.2 & 17.2 & 18.1 & 21.0 & 13.6 & 22.9 & 0.0 & 14.4 & 16.23 & 1.86 & 0.97 & 1.41 & $\mathrm{O}$ \\
\hline & 7.3 & 34.3 & 37.3 & 37.5 & 38.6 & 34.3 & 50.0 & 40.1 & 38.7 & 1.4 & 4.4 & 2.9 & $\mathrm{M}$ \\
\hline \multirow{3}{*}{8} & 8.1 & 11.4 & 6.5 & 11.7 & 0.0 & 10.4 & 0.0 & 5.53 & 6.01 & 0.49 & 5.39 & 2.94 & $\mathrm{O}$ \\
\hline & 8.2 & 51.4 & 46.9 & 50.4 & 50.6 & 42.9 & 0.0 & 35.98 & 41.4 & 5.46 & 10.0 & 7.73 & $\mathrm{~T}$ \\
\hline & 8.3 & 37.2 & 46.6 & 37.9 & 49.4 & 76.4 & 100 & 65.9 & 56.26 & 9.66 & 19.06 & 14.36 & $\mathrm{~T}$ \\
\hline
\end{tabular}

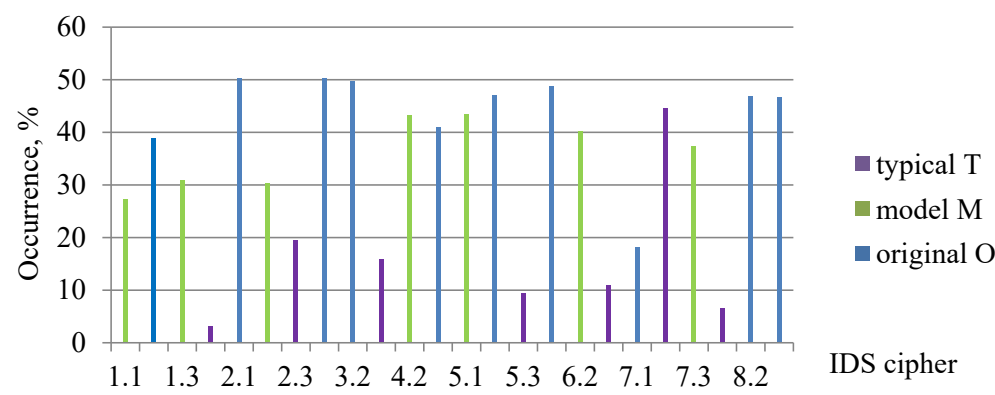

Fig. 4. Occurrence diagram of the individual design solutions for a men's jacket in the set $X_{2}$ of models-proposals 
Convolution matrix of the clusters of arranging the functional nodes of models of a men's jacket

Table 5

\begin{tabular}{|c|c|c|c|c|c|c|c|c|c|c|c|}
\hline \multirow{3}{*}{$\begin{array}{c}\text { FN } \\
\text { qty }-8\end{array}$} & \multirow{3}{*}{$\begin{array}{c}\text { IDS } \\
\text { qty }-24\end{array}$} & \multirow{2}{*}{\multicolumn{4}{|c|}{ Total estimated occurrences, $\%$ per sets }} & \multicolumn{2}{|c|}{ Total deviations, $\%$} & \multirow{3}{*}{$\Delta_{\text {aver }}$} & \multirow{2}{*}{\multicolumn{3}{|c|}{$\begin{array}{l}\sum \text { the number of typification } \\
\text { indices/occurrences in } X_{3}, \%\end{array}$}} \\
\hline & & & & & & \multirow{2}{*}{$\frac{\Delta_{1}}{\sum\left(\bar{X}_{3}-X_{2}\right)}$} & \multirow{2}{*}{$\frac{\Delta_{2}}{\sum\left(\bar{X}_{4}-X_{1}\right)}$} & & & & \\
\hline & & $X_{1}$ & $X_{2}$ & $X_{3}$ & $X_{4}$ & & & & $\mathrm{~T}$ & M & $\mathrm{O}$ \\
\hline \multirow{2}{*}{\multicolumn{2}{|c|}{$\begin{array}{l}\text { FN accumulated occur- } \\
\text { rences }\end{array}$}} & \multirow{2}{*}{801.1} & \multirow{2}{*}{800} & \multirow{2}{*}{814.88} & \multirow{2}{*}{797.55} & \multirow{2}{*}{99.76} & \multirow{2}{*}{205.23} & \multirow{2}{*}{152.5} & 10 & 7 & 7 \\
\hline & & & & & & & & & 462.54 & 241.73 & 93.28 \\
\hline \multicolumn{2}{|c|}{ Occurrence average, $C_{X_{i}}$} & 33.37 & 33.33 & 33.95 & 33.23 & 4.16 & 8.55 & 6.35 & 46.25 & 24.17 & 9.32 \\
\hline
\end{tabular}

$K_{c . u}$ and $K_{t . u}$. were calculated by the ratio of the sorted averages $C x_{i}$ :

$$
\begin{aligned}
& K_{\text {c.u. }}=\frac{C_{X_{4}}}{C_{T}}=\frac{33.23}{46.25}=0.72, \\
& K_{\text {t.u. }}=\frac{C_{\Delta_{2}}-C_{\Delta_{1}}}{C_{\Delta_{\text {aver }}}}=\frac{8.55-4.16}{6.35}=0.69 .
\end{aligned}
$$

Verification of the validity of image perception is characterized by the following distribution of points T-typical (traditional) - 3b; M-model (modern) - 2b; O-original (figurative) $-1 b$.

According to Table 5, the validity coefficient was determined from the formula:

$$
\begin{aligned}
& K v=\frac{T \times 3+M \times 2+O \times 1}{\sum I D S \times 3}= \\
& =\frac{10 \times 3+7 \times 2+7 \times 1}{24 \times 3}=\frac{51}{72}=0.71 .
\end{aligned}
$$

The cross-nostrification of IDS similarity in functional nodes confirms the grouping of ODR clusters around the base model of a typical representative (BM01).

The traditionality, modernity, and originality of the series' models are provided by the design modifications with replacement methods - a, connection (removal) - b. Sketch selection of prototype models of the industrial series of a men's jacket from the sorted industrial product range collection borrowed from the Internet [27] is given in Table 6 .

An encoded record of the complex functional solution for industrial series models is given in Table 7 .

Sketch verification of brand models for the design of industrial series

Table 6

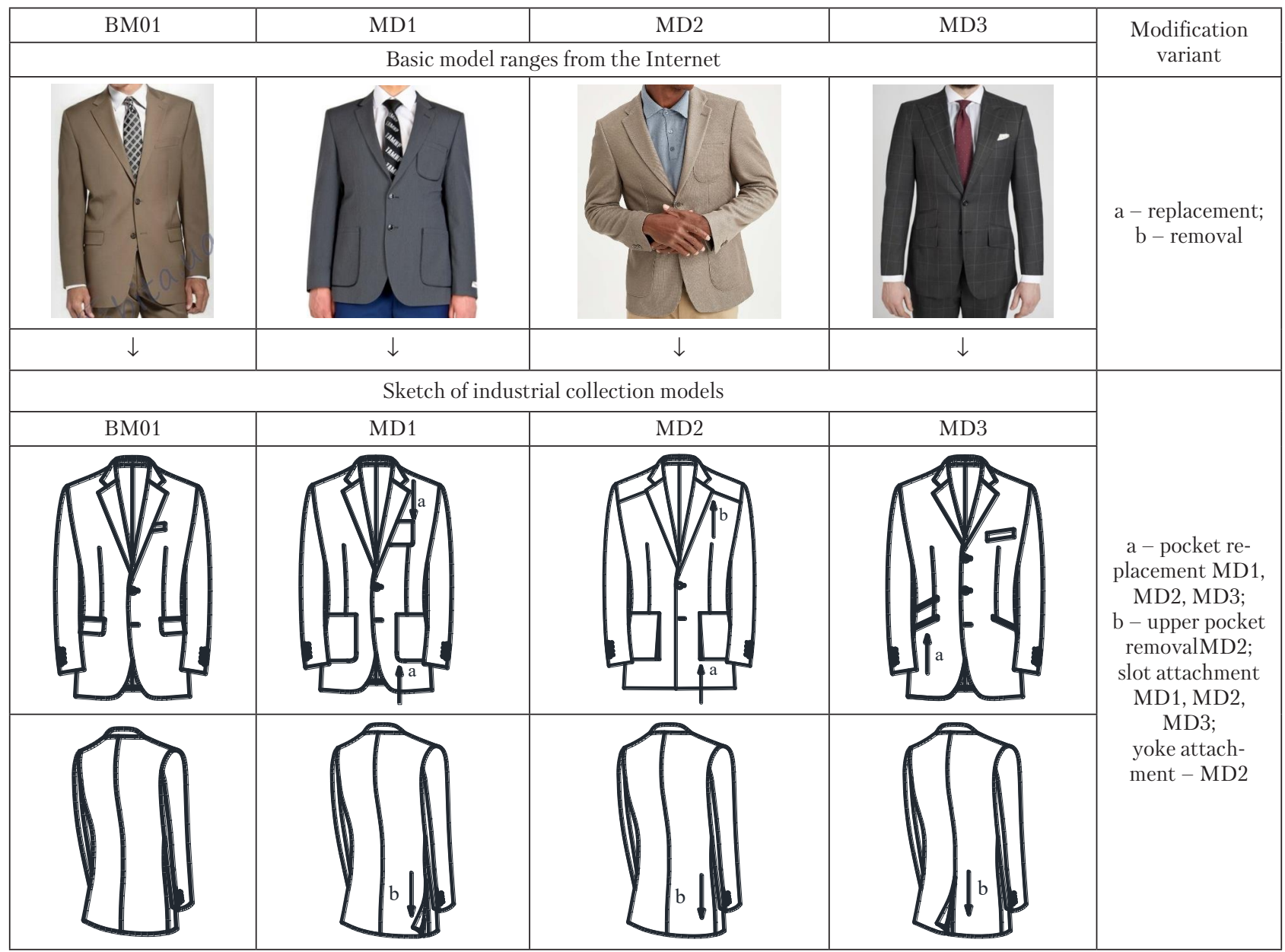


Encoded record of the sketch of industrial series IS (MD1-MD3)

\begin{tabular}{|c|c|c|c|c|c|c|c|c|c|c|}
\hline \multirow{2}{*}{ Model cipher } & \multicolumn{8}{|c|}{ FN and IDS code/ occurrence frequency, \% } & \multirow{2}{*}{$\begin{array}{l}\text { Accumulated } \\
\text { occurrence, \% }\end{array}$} & \multirow{2}{*}{$\begin{array}{c}\text { Average value of } \\
\text { occurrence } F N_{\text {aver }}, \%\end{array}$} \\
\hline & 1 & 2 & 3 & 4 & 5 & 6 & 7 & 8 & & \\
\hline \multirow{2}{*}{ IM01 } & 1.1 & 2.1 & 3.1 & 4.2 & 5.2 & 6.1 & 7.1 & 8.2 & \multirow{2}{*}{358.3} & \multirow{2}{*}{44.8} \\
\hline & 27.3 & 50.2 & 50.2 & 43.2 & 47.1 & 48.8 & 44.6 & 46.9 & & \\
\hline \multirow{2}{*}{ MD1 } & 1.2 & 2.2 & 3.1 & 4.2 & 5.2 & 6.2 & 7.3 & 8.2 & \multirow{2}{*}{334.2} & \multirow{2}{*}{41.8} \\
\hline & 38.8 & 30.4 & 50.2 & 43.2 & 47.1 & 40.3 & 37.3 & 46.9 & & \\
\hline \multirow{2}{*}{ MD2 } & 1.3 & 2.3 & 3.2 & 4.3 & 5.1 & 6.3 & 7.3 & 8.2 & \multirow{2}{*}{278.8} & \multirow{2}{*}{34.9} \\
\hline & 30.8 & 19.4 & 49.8 & 40.9 & 43.4 & 10.3 & 37.3 & 46.9 & & \\
\hline \multirow{2}{*}{ MD3 } & 1.2 & 2.1 & 3.2 & 4.3 & 5.1 & 6.1 & 7.1 & 8.2 & \multirow{2}{*}{363.1} & \multirow{2}{*}{45.4} \\
\hline & 38.8 & 50.2 & 49.8 & 40.9 & 43.4 & 48.8 & 44.6 & 46.6 & & \\
\hline$\sum \mathrm{FN}$ & 135.7 & 150.2 & 200.0 & 168.2 & 181.0 & 148.2 & 163.8 & 187.3 & 1334.4 & $\Sigma 166.9$ \\
\hline Aver FN & 33.9 & 37.5 & 50.0 & 42.05 & 45.25 & 37.5 & 40.95 & 46.82 & 41.74 & 41.73 \\
\hline Aver (MD1-MD3) & 36.13 & 33.3 & 49.9 & 41.7 & 44.6 & 33.13 & 39.6 & 46.5 & 40.61 & 40.7 \\
\hline
\end{tabular}

The basic base BM01 with a two-buttons clast is unified. Methods of replacement, attachment (removal) allow one to consider pockets and slots as aggregates of unified nodes. The discrepancy in the average values of $F N_{\text {aver }}$ is $1.03 \%$. Consequently, this confirms the belonging of industrial series models to the set of the functional series $X_{1} \subset X_{2}, \bar{X}_{4}=X_{1} \cup X_{2}$.

\section{Discussion of results of studying the impact of typifying a design idea on the sorting of structural elements' codes}

The periodic repeatability of the cyclic nature of fashion confirmed the viability of the classic shape of a five-seam design of the men's jacket from the positions of silhouette transitivity (Fig. 1). The difficulty of changing the design idea over time is in the fact that the tightness of interrelation in the types of modifications of metric characteristics is subject to confrontation in the development of plastic and geometric shapes. That does not contradict the practical data from $[8,12]$. Mathematical modeling of the dynamics of updating mobile elements of the shape (Fig. 2) indicates the possibility of using the clusters of typical elements (Table 2). The mechanism of taking into consideration the metric characteristics of the classic shape of a five-seam jacket involves the convolution of modification parameters during the structural and compositional sorting of the base basis.

In this sense, the formation of the basis of statistical sets of models, taking into consideration the level of typical representation in the shape of a basic model [15] is of particular interest. The use of communication and associativity properties for comparing samples indicates the feasibility of a parallel encoding method in order to limit the size of the matrix (Table 3). The use of the matrix approach to the modification of classification traits eliminates the likelihood of skipping or re-examination of the structural element in the combination.

The use of the method of sorting models to view Internet resources is based on the selection of branded image collec- tions of a typical representative. In industrial collections, model series are represented by blocks of style lines [7].

The results of estimation studies of sample sets (Table 4) indicate the mechanism of convolution of layout clusters by processing cumulative occurrences in functional nodes by operations of including the series of individual structural elements.

The obtained levels of modifications (Table 7) confirm the ambiguity of the entry of sets of structural and compositional solutions of men's jacket models into the morphological field of unification of style features. However, in contrast to the results of studies on the impact of modification parameters on variations of silhouetted margins [21], the obtained data suggest a method for assessing the uniformity of industrial collection models according to the level of typification of control measurements of the finished jacket in technical documentation. The procedure of verification of the value of the image for the consumer [26] makes it possible to adjust the clusters of group characteristics of style, taking into consideration the parameters of functional feasibility.

A potentially interesting area for further research of fashion cycles in a men's jacket is the selection of diffuse styles to differentiate the age groups of psychological types of the consumer, presented in [27]. The analytical method of fixing the reference points for changing the cycle of shape development makes it possible to offer sketch layouts of industrial collection models. Therefore, it is necessary to carry out research on sorting the parameters of style varieties in the product range of control measurements of technical documentation.

\section{Conclusions}

1. Our study has proven the impact of the accumulation of quantitative changes in the style features of the design idea in qualitative changes in shape. The tectonic basis of the product design provides a theoretical justification for predictive models of object image recognition. Due to this, it can be 
argued that there is transitivity in the process of modification transformations of metric properties of the shape. Correlation analysis of the 15-year cycle of structural characteristics of shape confirmed the preservation in the XXI century of three silhouette modifications of the five-seam jacket design with a typical structure of eight functional nodes. The base silhouette is semi-fitting $-61.8 \%$.

2. Investigating the transitivity of classification features of appearance in the ordered sets of sample from 2000-2020 allows one to identify functional nodes in the matrix of interactive sorting according to the schemes of accumulation of frequency of occurrence. The size of the compatibility matrix of $24 \times 24$ remains unchanged due to compliance with the conditions $X_{1} \subset X_{2} ; \bar{X}_{3} \in X_{2} ; \bar{X}_{4} \subset X_{1} \cup X_{2}$. The square matrix makes it possible to apply a method of the morphological box. The matrix sparsity coefficient characterizes the productivity of combinations $m_{\bar{x}_{3}}=0.183 ; m_{\bar{x}_{4}}=0.184$.

3. The procedure for evaluating the effectiveness of an interactive selection of options for the structural and technological solutions of a men's jacket combines the plastic shape of the design idea and the production feasibility of using a typical five-seam structure. This is confirmed by the uniformity of the average values of cumulative occurrences by the typification indexes: $K_{c . u}=0.72, K_{t . u .}=0.69 ; K_{v}=0.71$. The encoded record of a sketch of the industrial series according to the results of structural and technological uniformity of interchangeable models confirms the belonging of the sample to the typological series.

\section{References}

1. Yang, Z., Kim, C., Laroche, M., Lee, H. (2014). Parental style and consumer socialization among adolescents: A cross-cultural investigation. Journal of Business Research, 67 (3), 228-236. doi: https://doi.org/10.1016/j.jbusres.2013.05.008

2. KHonguang, E., Disskaya, T. N., Kuz'michev, V. E. (2006). Izuchenie konstruktivnogo napravleniya mody v muzhskikh kostyumakh vtoroy poloviny XX - nachala XXI veka. Chast' II. zakonomernosti izmeneniya konstruktivnykh parametrov muzhskikh pidzhakov. Shveynaya promyshlennost', 2, 53-55. Available at: https://www.elibrary.ru/contents.asp?id=33376687

3. Nayak, R., Padhye, R., Wang, L., Chatterjee, K., Gupta, S. (2015). The role of mass customisation in the apparel industry. International Journal of Fashion Design, Technology and Education, 8 (2), 162-172. doi: https://doi.org/10.1080/17543266. 2015.1045041

4. Nasibov, E., Demir, M., Vahaplar, A. (2019). A fuzzy logic apparel size decision methodology for online marketing. International Journal of Clothing Science and Technology, 31 (2), 299-315. doi: https://doi.org/10.1108/ijcst-06-2018-0077

5. Hong, Y., Bruniaux, P., Zeng, X., Curteza, A., Liu, K. (2018). Design and evaluation of personalized garment block for atypical morphology using the knowledge-supported virtual simulation method. Textile Research Journal, 88 (15), 1721-1734. doi: https:// doi.org/10.1177/0040517517708537

6. Voroncova, E. A., Danilova, O. N., Slesarchuk, I. A. (2015). Combined method with 3D design for creation complex shapes of costume. Fundamental research, 7 (1), 111-115. Available at: https://s.fundamental-research.ru/pdf/2015/7-1/38735.pdf

7. Slavinska, A. L., Mytsa, V. V., Syrotenko, O. P., Dombrovska, O. M. (2021). Method of optimization of geometric transformations of design surfaces of a man's jacket. IOP Conference Series: Materials Science and Engineering, 1031 (1), 012021. doi: https:// doi.org/10.1088/1757-899x/1031/1/012021

8. Elizarov, A. A. (2011). Razvitie stilisticheskikh form muzhskogo klassicheskogo kostyuma i ikh prognozirovanie. Dizayn i Tekhnologii, 26 (68), 12-24. Available at: https://www.elibrary.ru/contents.asp?id=33819779

9. Zarezade, T., Payvandy, P. (2019). 3D Garment Design using Interactive Genetic Algorithm and Clustering. Trends in Textile Engineering \& Fashion Technology, 5 (1). doi: https://doi.org/10.31031/tteft.2019.05.000604

10. Gavish, Y., Shoham, A., Ruvio, A. (2010). A qualitative study of mother-adolescent daughter-vicarious role model consumption interactions. Journal of Consumer Marketing, 27 (1), 43-56. doi: https://doi.org/10.1108/07363761011012949

11. Paço, A., Leal Filho, W., Ávila, L. V., Dennis, K. (2020). Fostering sustainable consumer behavior regarding clothing: Assessing trends on purchases, recycling and disposal. Textile Research Journal, 91 (3-4), 373-384. doi: https://doi.org/10.1177/0040517520944524

12. Slavinskaya, A. L., Troyan, G. F. (1989). Prognozirovanie dinamiki razvitiya konstruktivnykh resheniy bytovoy odezhdy. Izvestiya vysshikh uchebnykh zavedeniy. Tekhnologiya legkoy promyshlennosti, 1, 72-75.

13. Johnson, K., Lennon, S. J., Rudd, N. (2014). Dress, body and self: research in the social psychology of dress. Fashion and Textiles, 1 (1). doi: https://doi.org/10.1186/s40691-014-0020-7

14. Porterfield, A., Lamar, T. A. M. (2016). Examining the effectiveness of virtual fitting with 3D garment simulation. International Journal of Fashion Design, Technology and Education, 10 (3), 320-330. doi: https://doi.org/10.1080/17543266.2016.1250290

15. Slavinska, A. L., Mytsa, V. V. (2021). Innovative technologies of modular design of constructive-unified series of stable assortment. Fashion Industry, 2, 34-42. doi: https://doi.org/10.30857/2706-5898.2021.2.2

16. Slavinska, A., Mytsa, V. (2021). Functional aspect of grouping unified forms of working documentation on the model of production clothing. Herald of Khmelnytskyi National University, 2 (295), 254-258. doi: https://doi.org/10.31891/2307-5732-2021295-2-254-258

17. Kozlova, T. V., Stepuchev, R. A., Petushkova, G. I., Rytvinskaya, L. B., Rybkina, E. A., Yakovleva, N. B. (1988). Osnovy teorii proektirovaniya kostyuma. Moscow: Legprombytizdat, 352. 
18. Mok, P. Y., Xu, J., Wu, Y. Y. (2016). Fashion design using evolutionary algorithms and fuzzy set theory - a case to realize skirt design customizations. Information Systems for the Fashion and Apparel Industry, 163-197. doi: https://doi.org/10.1016/b9780-08-100571-2.00009-9

19. Pei, J., Fan, J., Ashdown, S. P. (2020). A novel optimization approach to minimize aggregate-fit-loss for improved breast sizing. Textile Research Journal, 90 (15-16), 1823-1836. doi: https://doi.org/10.1177/0040517519901318

20. Kim, Y.-K., Sullivan, P. (2019). Emotional branding speaks to consumers' heart: the case of fashion brands. Fashion and Textiles, 6 (2). doi: https://doi.org/10.1186/s40691-018-0164-y

21. Slavinska, A., Mytsa, V., Syrotenko, O., Dombrovska, O. (2021). Devising a method to parametrize the jacket style varieties through the modification of tipological series structures. Eastern-European Journal of Enterprise Technologies, 3 (1 (111)), 92-105. doi: https://doi.org/10.15587/1729-4061.2021.232014

22. Guo, M., Kuzmichev, V. E., Adolphe, D. C. (2015). Human-Friendly Design of Virtual System «female Body-dress». Autex Research Journal, 15 (1), 19-29. doi: https://doi.org/10.2478/aut-2014-0033

23. Kuz'mina, O., Silaeva, M. (2010). Pidzhak: noviy siluet. Atel'e, 4, 28-35.

24. Galadaseva, G. (2007). Evolyutsiya kroya. Muzhskoy kostyum na styke vekov: klassicheskie obraztsy muzhskoy odezhdy. Atel'e, 3, 49-51.

25. Cholovichyi odiah Versace - suchasni trendy v cholovichiy modi. Available at: http://crazytrend.com.ua/cholovichij-odyagversace-suchasni-trendi-v-cholovichij-modi/

26. Tsennosti potrebiteley v strategiyakh brendov: kak pokupatel'skoe povedenie menyaet litso riteyla (2020). Retail\&Loyalti, 8 (95). Available at: https://retail-loyalty.org/journal_retail_loyalty/read_online/art2916238/

27. Muzhskie kostyumy 2020-2021 goda - modnye tendentsii. Available at: https://www.pinterest.com/pin/834221530971602490/ 